\title{
Influence of phosphorus and silicon on lipid class production by the marine diatom Chaetoceros gracilis grown in turbidostat cage cultures
}

\author{
A. T. Lombardi, P. J. Wangersky* \\ Department of Oceanography, Dalhousie University, Halifax, Nova Scotia, Canada B3H 4J1
}

\begin{abstract}
Production of intracellular and extracellular lipid classes by Chaetoceros gracilis was studied over a wide range of supply rates of inorganic phosphorus and silicon. The cage culture turbidostat, a continuous culture technique providing closely controlled nutrient concentrations and population densities, was used for growing the diatom. Nutrient, intracellular lipid and chlorophyll $a$ analyses were performed over the whole range of nutrients used, but dissolved lipid production was measured only at the extremes of the ranges of nutrient concentrations. The production of triglycerides, a storage class of lipids, was triggered by nutrient stress with either phosphorus or silicon, as had earlier been demonstrated with nitrogen. The synthesis of phospholipids was reduced under phosphorus stress, while the synthesis of chlorophyll a was increased by silicon stress. The increase in chlorophyll a per cell under silicon stress brings into question the use of this pigment as a measure of biomass. Particulate lipid yield was highest in intermediate concentrations of both nutrients.
\end{abstract}

\section{INTRODUCTION}

The production and storage of lipids by phytoplankton cells has been shown to be regulated by environmental factors such as nutrient supply and light intensity; several species accumulate total lipids as a result of nutrient stress. In most cases the effects of nitrogen or silicon depletion have been studied (Collyer \& Fogg 1955, Fogg 1956, Shifrin \& Chisholm 1981, Taguchi et al. 1987, Mortensen et al. 1988, Roessler 1988, Emdadi \& Berland 1989). Since lipids are an operationally defined heterogeneous group of compounds, the study of changes in lipid classes under conditions of nutrient stress could produce more information than can be obtained from the measurement of total lipid content alone. Such investigations have shown that the accumulation of total lipids under nutrient depletion is due to an increase in a neutral lipid class (Opute 1974, Morris et al. 1983) which migrates together with triglycerides in a TLC/FID chromatography system (Parrish 1987a, Parrish \& Wangersky 1987, 1990). That these were, in fact, triglycerides was demonstrated by Gershey \& Wangersky (1986), using high-resolution gas

\footnotetext{
- Addressee for correspondence
}

chromatography. Several studies have been conducted on changes in intracellular lipid content with nutrient stress, but few studies are available on nutrient effects on extracellular release of these compounds (Parrish \& Wangersky 1987).

The present study analyses the effects of a range of supply rates of silicon and phosphorous on the production of intracellular and extracellular lipid classes of the diatom Chaetoceros gracilis. Nitrogen limitation was not included since such a study had already been completed (Parrish \& Wangersky 1990). Cultures were grown in a modified version (Parrish \& Wangersky $1987)$ of the cage culture turbidostat originally described by skipnes et al. (1980). This system of continuous culture maintains a constant nutrient supply by passing new medium continuously through the growth 'cage', a transparent chamber in which the cultures are retained by filters or screens on the inflow and exit ports. A constant cell density within the growth chamber is maintained by active removal of excess cells from the chamber, the amount to be removed being determined by continuous measurement of turbidity within the growth chamber. Further descriptions of the technique and examples of its use can be found in Parrish \& Wangersky (1987), Roy (1988) and Zhou \& Wangersky (1989). 


\section{METHODS}

The initial culture of the marine diatom Chaetoceros gracilis was graciously supplied by Dr Garry Newkirk, of the Department of Biology, Dalhousie University, Halifax, Canada. Four cage culture turbidostat units (Manna Marine Enterprises, Halifax) were employed, each nutrient concentration being run in duplicate. The volume of each culture chamber was $350 \mathrm{ml}$, but the chambers were filled only to $300 \mathrm{ml}$. Filters with a $3 \mu \mathrm{m}$ pore size (Versapor 66300, Gelman Sciences) closed the cage at the inlet and exit ports. A low deadvolume 4 -port reversing valve was placed in the inlet and outlet lines in order to reverse the direction of flow of medium into the chamber at regular intervals, to prevent clogging of the exit filter. Excess organisms were harvested by a peristaltic pump controlled by an LED and a photodetector. Upper and lower limits for harvesting could be set on the unit controller; the practical limit on the harvesting window was the point at which the pump began to chatter.

The medium used was based on seawater taken from the Northwest Arm, a marine inlet of Halifax Harbour, Nova Scotia. The seawater was sandbed filtered in the facilities of the Dalhousie Aquatron, then pressure dialyzed (Amicon Diaflo) to remove everything with a molecular weight greater than $3000 \mathrm{D}$. Nutrients, trace metals, and vitamins were added to bring the medium to the level of a modified Harrison et al. (1980) medium, the modification being a doubling of the thiamine- $\mathrm{HCl}$ content. Phosphorus was supplied as $\mathrm{NaH}_{2} \mathrm{PO}_{4}$ and silicon as $\mathrm{Na}_{2} \mathrm{SiO}_{3}$. Approximately $2.4 \mathrm{l}$ of fresh medium passed through each growth chamber each day. While $\mathrm{pH}$ was not measured in these experiments, at the cell density used $\left(3.0 \times 10^{8}\right.$ cells $\left.\mathrm{ml}^{-1}\right)$ we have never seen $\mathrm{pH}$ changes in other experiments. At these nutrient levels, we have grown turbidostat cage cultures of Chaetoceros gracilis to $9 \times 10^{7}$ cells $\mathrm{ml}^{-1}$, at which point light, rather than $\mathrm{CO}_{2}$ or $\mathrm{pH}$, became limiting.

Both nutrients were supplied at 7 different rates; phosphorus from $9 \mathrm{pg} \mathrm{cell}-1 \mathrm{~d}^{-1}$ to $0.3 \mathrm{pg} \mathrm{cell}^{-1} \mathrm{~d}^{-1}$. and silicon from $80 \mathrm{pg}$ cell ${ }^{-1} \mathrm{~d}^{-1}$ to $4 \mathrm{pg} \mathrm{cell}^{-1} \mathrm{~d}^{-1}$. Nutrients were measured both entering and leaving the growth chambers, phosphorus by the method of Strickland \& Parsons (1972) and silicon as described in Koroleff (1976). Chlorophyll a was measured by the method of Talling \& Driver (1961), using a Turner fluorometer.

Cell densities were kept constant at $3.0 \times 10^{8}$ cells $\mathrm{ml}^{-1}$ throughout the experiments. As a check on the functioning of the turbidostat, cell concentrations and size distributions were measured daily with a Coulter Counter, Model $1015 \mathrm{ZB}$. Culture temperatures were held at $20^{\circ}\left( \pm 1 \mathrm{C}^{\circ}\right)$, and light intensity at $80 \mathrm{E} \mathrm{m}^{-2} \mathrm{~s}^{-1}$
(LI-185 Quantum Photometer, Lasmbda Instruments) with a $16: 8$ light: dark cycle.

Growth rates were calculated according to Skipnes et al. (1980). The specific growth rate $\mu$ was calculated as the proportion of the volume of the growth chamber $V$, harvested in a day:

$$
\mu=\mathrm{H} / \mathrm{V}
$$

where $\mathrm{H}=$ volume harvested per day. The number of divisions per day is given by

$$
\mathrm{d}=\mu / \ln 2
$$

Intracellular lipids were extracted by filtering $50 \mathrm{ml}$ of culture through a glass fiber filter (Whatman GF/C, previously baked overnight at $400^{\circ} \mathrm{C}$ ), then sonicating the filter in dichloromethane:methanol $(2: 1) \mathrm{V} / \mathrm{V}$ and again in $100 \%$ dichloromethane. The extract was then washed with organic-free water; this water was prepared by passing distilled water through a Millipore Super- $Q$ system, then passing the water vapor at $800^{\circ} \mathrm{C}$ through a packed silica column in a stream of oxygen to remove trace organics. Extracellular lipids were extracted from both the incoming and exiting medium by filtering $400 \mathrm{ml}$ of sample and extracting 3 times with dichloromethane, once at $\mathrm{pH} 8$ and twice at $\mathrm{pH} 2$. Total procedure blanks were run on each day of analysis, and all samples were spiked with an internal standard (hexadecanone-3-one) immediately after filtration to measure recovery efficiency. Lipid class analyses were performed on an Iatroscan TH10-MkIII (Iatron Laboratories, Tokyo) using the procedure described in detail in Parrish (1987b). For all the analyses in this investigation, the latroscan instrument variables were: hydrogen flow rate $173 \mathrm{ml} \mathrm{min}^{-1}(0.85 \mathrm{~mm} \mathrm{Hg})$, scan velocity $4.2 \mathrm{~mm} \mathrm{~s}^{-1}$, attenuation $16 \mathrm{mV}$. Total intracellular lipid yields were calculated as the product of the duplication time and the sum of the lipid class compositions, while total extracellular lipid yields were calculated from the sum of the differences in lipid class composition between medium entering and exiting from the growth chamber.

\section{RESULTS}

At very low supply rates, the proportion of phosphorus used per cell, compared to that offered, reached $100 \%$. Silicon, on the other hand, was not taken up appreciably at the 2 lowest rates of supply (Fig. 1). The 2 lowest rates of supply of both nutrients limited growth sharply (Fig. 2). At higher rates of supply the proportion of phosphorus taken up per cell decreased in an approximately linear fashion; at all rates of uptake found in these experiments, growth rates increased with increasing phosphorus use. In the case of silicon, a 

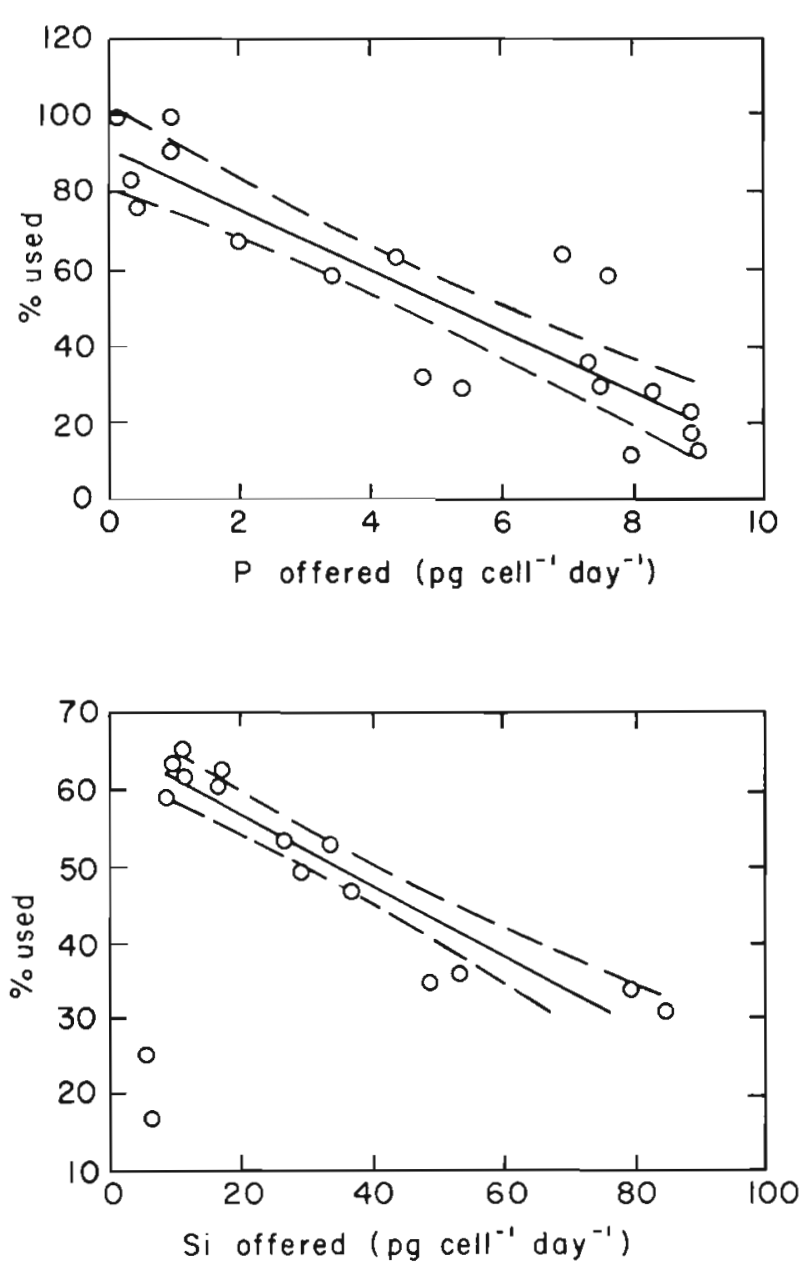

Fig. 1. Chaetoceros gracilis. Nutrient used as a percentage of that offered to each cell per day. Dashed outer lines: $95 \%$ confidence limits. $\% \mathrm{P}$ used $=91.87-8.04$ ( $\mathrm{P}$ offered), $\mathrm{r}=$ $0.90, \mathrm{p}<0.01, \mathrm{n}=21 . \%$ Si used $=66.06-0.46$ (Si offered) ,

$$
\mathrm{r}=0.94, \mathrm{p}<0.01, \mathrm{n}=16
$$

similar decrease in proportion used was seen after the 2 lowest supply rates. However, above an uptake rate of $10 \mathrm{pg} \mathrm{cell}{ }^{-1} \mathrm{~d}^{-1}$ the growth rate remained roughly constant. While a good correlation was found between (Doublings $d^{-1}$ ) and (ln Si offered), the scatter at the upper end of the scale were values at what were essentially constant growth rates.

Chlorophyll a synthesis was affected by the rates of supply of either nutrient, but in opposing fashions (Fig. 3). Phosphorus limitation clearly resulted in a decrease in chlorophyll per cell, while silicon limitation brought about an increase in cellular chlorophyll.

When nutrients were not limiting, triglycerides (TG) and free fatty acids (FFA) were produced in similar amounts, and always below $6 \%$ of the total lipids (Table 1). Free fatty acids and free sterols were detected only in unstressed cells. Under nutrient stress
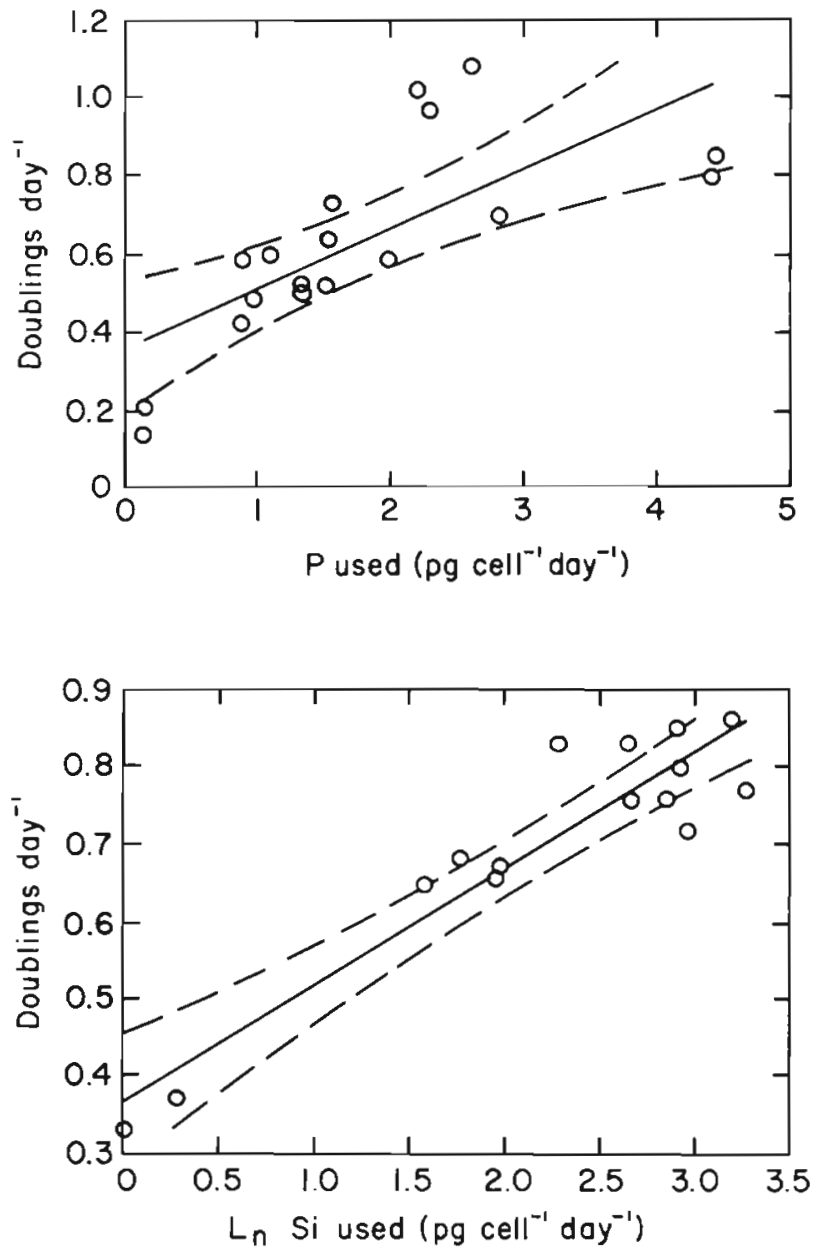

Fig. 2. Chaetoceros gracilis. Growth rate (doublings $d^{-1}$ ) as function of the rate of nutrients used per cell. $\mathrm{D} \mathrm{d}^{-1}=0.36+$ 0.15 (P used), $\mathrm{r}=0.72, \mathrm{p}<0.01, \mathrm{n}=15 . \mathrm{D} \mathrm{d}^{-1}=0.37+0.15$ (ln Si used), $r=0.93, p<0.01, n=15$

with either phosphorus or silicon, the major lipid component was the triglyceride fraction (Fig. 4). Nutrient stress could be detected in this species by a lipid content of more than $0.5 \mathrm{pg}$ cell $^{-1}$ of triglycerides. Acetone mobile polar lipids (AMPL) and phospholipids (PL) were significant components in all chromatograms; their increase with increasing nutrient uptake is shown in Figs. $5 \& 6$. The decrease in phospholipids at the highest rates of silicon uptake warrants further investigation.

The sum of total lipids per cell (Fig. 7) was a function of the phosphorus and silicate used, as was the triglyceride (Fig. 8). In both cases, a good inverse correlation between nutrients used and lipid content was found at the lower nutrient levels. The intracellular lipid yield for the culture did not increase under silicon stress, although a weak correlation could be seen with phos- 
phorus stress (Fig. 9); the increase in triglyceride production per cell was more than offset by the reduction in population growth.

The production of intracellular and extracellular lipid classes by both stressed and unstressed cells is shown
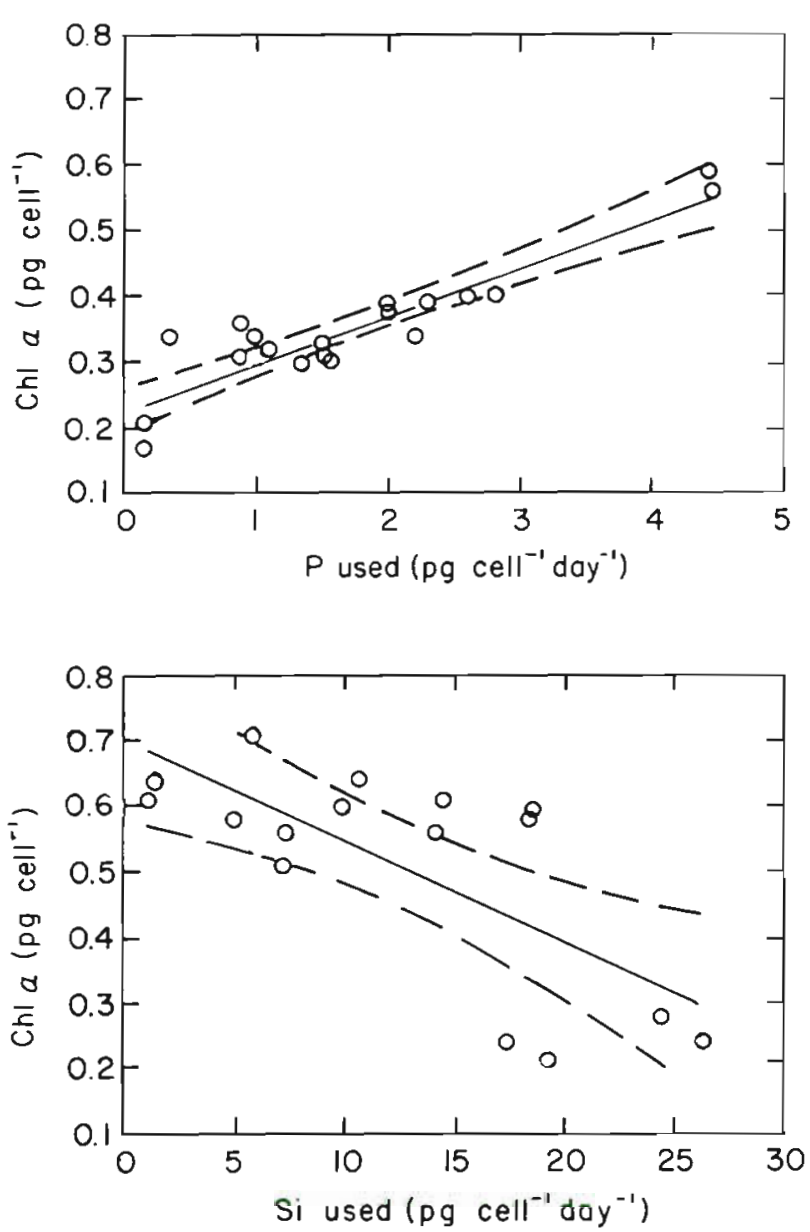

Fig. 3. Chaetoceros gracilis. Production of chlorophyll a as function of rate of nutrients used per cell. Chl $a=0.23+$ $0.07(\mathrm{P}$ used), $\mathrm{r}=0.91, \mathrm{p}<0.01, \mathrm{n}=20$. Chl $a=0.70-$ 0.02 (Si used), $r=0.72, \mathrm{p}<0.01, \mathrm{n}=13$ in Table 1. No relationship was found between concentrations of nutrients in the medium and the extracellular lipids, except that larger amounts of phospholipids were found in the extracellular fraction of stressed cultures.
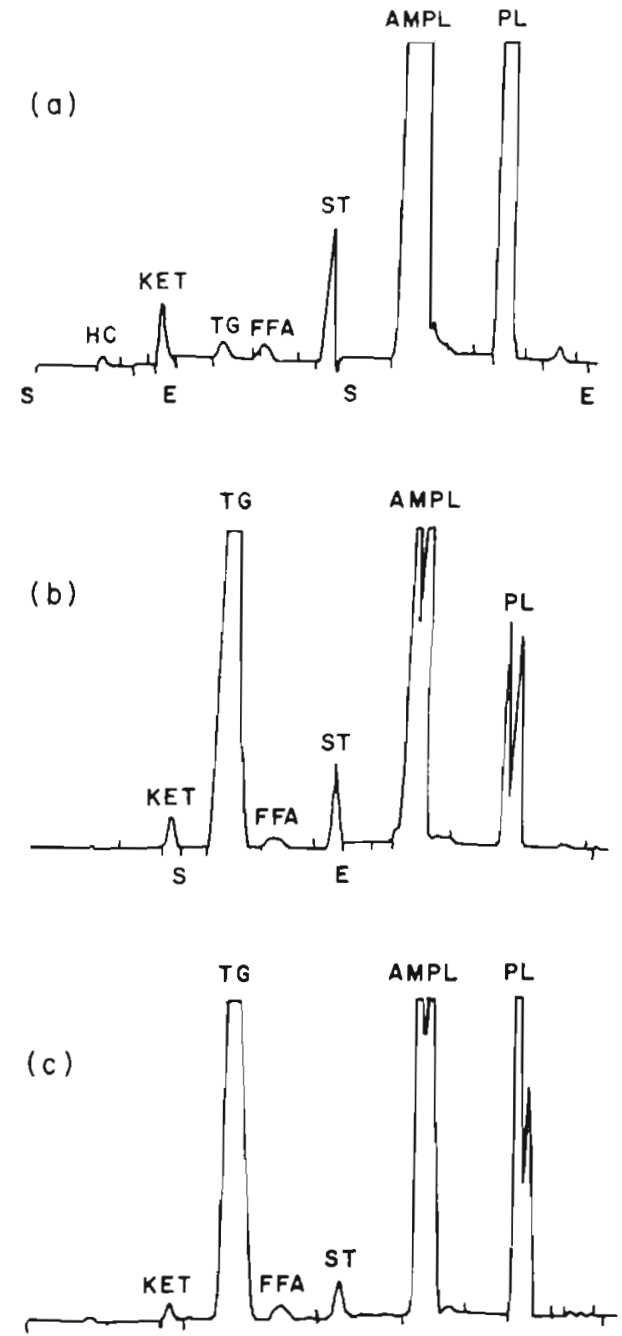

Fig. 4. Chaetoceros gracilis. TLC/FID chromatograms of cells in 3 different physiological states. (a) Healthy cells, (b) phosphorus deficient cells, (c) silicon deficient cells. S: start, E: end of scan

Table 1. Chaetoceros gracilis. Production of intracellular and extracellular lipid classes in cells cultivated under conditions of sufficiency and deficiency of phosphorus or silicon. All values in picograms per cell

\begin{tabular}{|c|c|c|c|c|c|c|}
\hline \multirow[t]{2}{*}{ Lipid class } & \multicolumn{2}{|c|}{ Healthy cells } & \multicolumn{2}{|c|}{ Phosphorus stressed } & \multicolumn{2}{|c|}{ Silicon stressed } \\
\hline & Intracell & Extracell. & Intracell. & Extracell. & Intracell. & Extracell. \\
\hline $\mathrm{HC}$ & 0.02 & 0.01 & 0.02 & - & - & - \\
\hline TG & 0.06 & - & 2.03 & 0.05 & 2.85 & - \\
\hline FFA & 0.08 & 0.07 & 0.56 & 0.02 & 0.14 & - \\
\hline ST & 0.17 & 0.02 & 0.13 & 0.01 & 0.29 & 0.01 \\
\hline AMPL & 1.37 & - & 0.84 & - & 1.06 & 0.01 \\
\hline PL & 1.09 & 0.03 & 0.32 & 0.06 & 0.85 & - \\
\hline Total & 2.79 & 0.13 & 3.90 & 0.14 & 5.73 & 0.02 \\
\hline
\end{tabular}



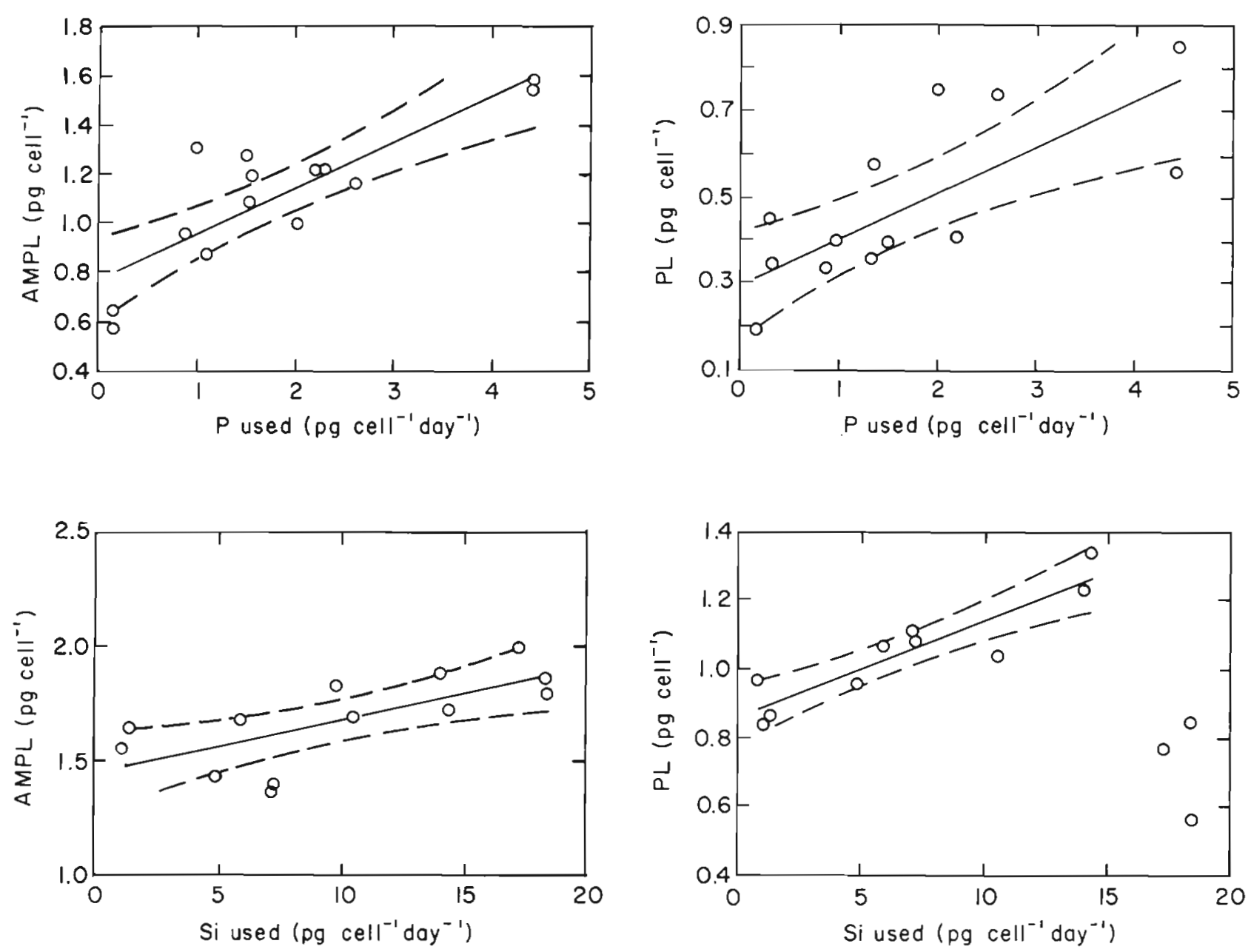

Fig. 5. Chaetoceros gracilis. Production of Acetone Mobile Polar Lipids (AMPL) as function of rate of nutrient used per cell. AMPL $=0.78+0.19$ (P used), $\mathrm{r}=0.84, \mathrm{p}<0.01, \mathrm{n}=14$

AMPL $=1.46+0.02$ (Si used), $r=0.70, p<0.01, n=13$

\section{DISCUSSION}

The effect of silicon concentration on uptake and growth rate of Chatoceros gracilis was clearly different from that of phosphorus. At low concentrations, phosphorus, like nitrogen (Parrish \& Wangersky 1990), was virtually cleared from the medium; with silicon, there appeared to be a threshold concentration below which it was taken up only minimally. Increased uptake of phosphorus or nitrogen resulted in sharply increased growth rates over a short range of nutrient uptake, followed by a slower increase which continued over the whole range of nutrient supply tested in both $C$. gracilis and Phaeodactylum tricornutum (Parrish \& Wangersky 1987), while uptake of silicon above $10 \mathrm{pg} \mathrm{cell}^{-1} \mathrm{~d}^{-1}$ by C. gracilis appeared to result in a constant growth rate. This is not surprising; if the maximum growth rate is set

Fig. 6. Chaetoceros gracilis. Production of Phospholipids (PL) as function of rate of nutrient used per cell. $\mathrm{PL}=0.30+0.11(\mathrm{P}$ used), $\mathrm{r}=0.76, \mathrm{p}<0.01, \mathrm{n}=14 . \mathrm{PL}=0.86+0.03$ (Si used), $\mathrm{r}=$ $0.91, \mathrm{p}<0.01, \mathrm{n}=11$

by the nitrogen or phosphorus available, once this growth rate is reached, addition of silicon should not result in any further rate increase. We would suggest that under our culture conditions, phosphorus was probably setting the growth rate, since additions of phosphorus did result in growth rates greater than the roughly 0.8 doublings $\mathrm{d}^{-1}$ plateau of the silicon experiment.

What is perhaps surprising is that even at nutrient supply rates at which the nutrient is greatly in excess, and is largely not taken up, a further increase in nutrient can result in an increase, albeit small, in growth rate. There must be some limit above which the machinery of reproduction in diatoms cannot be driven; this limitation can probably only be seen in some form of continuous culture where the population density can be held between narrow limits, thereby excluding the effects of nutrient depletion and of light 

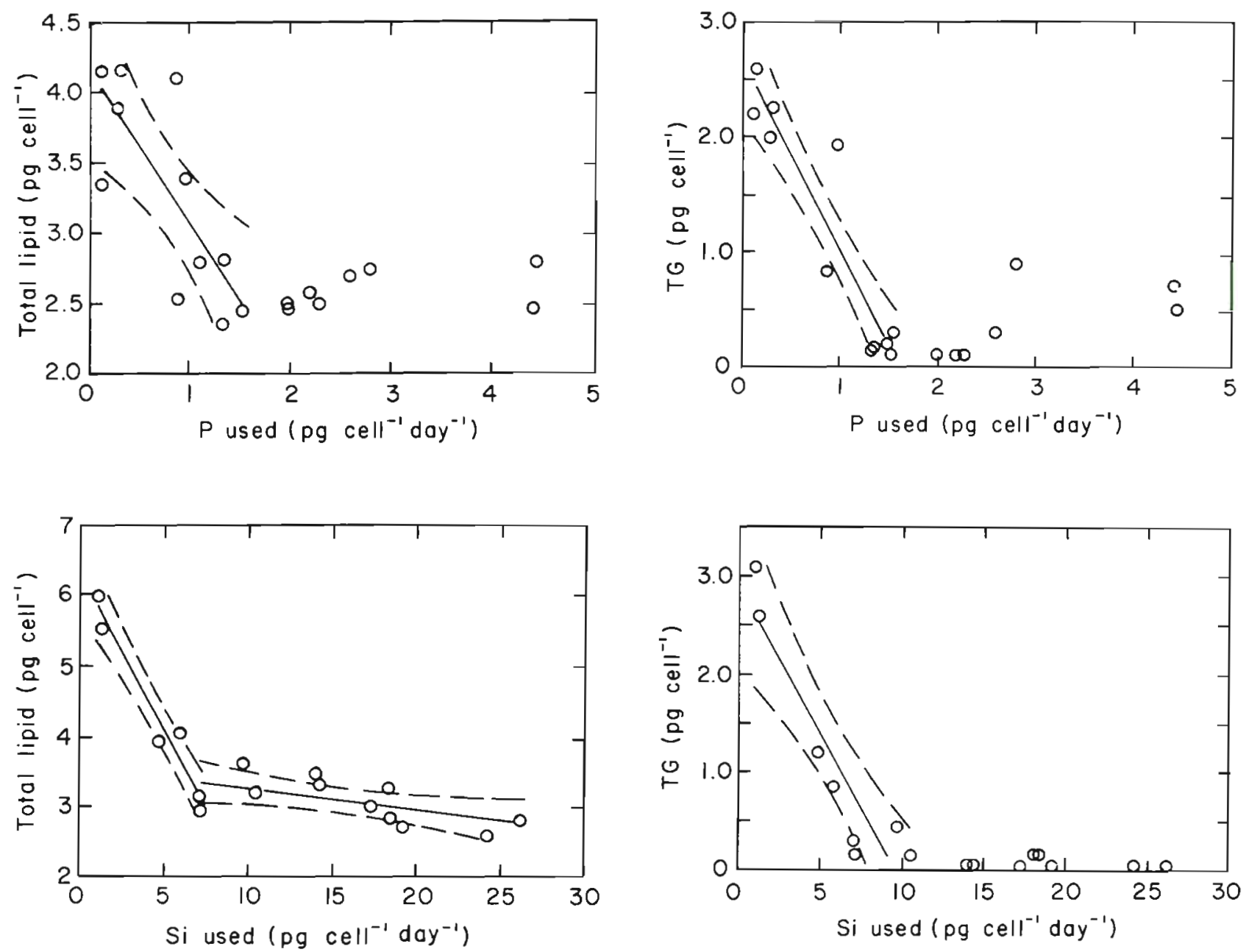

Fig. 7. Chaetoceros gracilis. Sum of Iatroscan-measured particulate lipid classes as function of the rate of nutrient used per cell. Total lipid $=4.17-1.09$ ( $\mathrm{P}$ used), $\mathrm{r}=0.78, \mathrm{p}<0.01, \mathrm{n}=$ 11. Total lipid, low $\mathrm{Si}_{1}=6.29-0.44$ (Si used), $r=0.98$, $\mathrm{p}<0.01, \mathrm{n}=7$. Total lipid, high $\mathrm{Si}_{,}=3.56-0.03$ (Si used), $\mathrm{r}=0.61, \mathrm{p}<0.05, \mathrm{n}=11$

limitation due to self-shading. With cage culture techniques, the logical experiment would be to increase the supply of all nutrients by increasing the flow rate of the medium until no further increase in growth rate could be achieved. The increase in flow rate in itself does not seem to limit growth; we have used flow rates of the order of $1 \mathrm{l} \mathrm{min}^{-1}$ in order to test the functioning of the filter units, with no adverse effects on diatom growth rates.

These results suggest that in natural populations under bloom conditions, rates of increase of the phytoplankton population are determined by nutrient concentrations even when nutrients are greatly in excess. Increasing population density resulting in light limitation obscures the effects on the growth rate of the diminishing nutrient concentration until those concentrations are reached

Fig. 8. Chaetoceros gracilis. Production of Triglycerides (TG) as function of the rate of nutrient used per cell. TG $=$ $2.67-1.65$ (P used), $r=0.94, p<0.01, n=10 . T G=2.90-$ 0.30 (Si used), $r=0.92, p<0.01, n=8$

which are severely restrictive. In order to estimate primary productivity in the absence of actual measurement of this quantity, we must be concerned with the effects of nutrient concentrations not only when they are limiting, but also when they are in apparent excess.

\section{Intracellular lipids}

This work, along with the work of Parrish \& Wangersky $(1987,1990)$, has clearly demonstrated the triggering effect of nutrient stress on triglyceride accumulation in some species of diatoms. A similar switch in natural populations at the end of the spring bloom has been documented by Parrish (1987b). If this effect proves to be general, triglyceride content may 

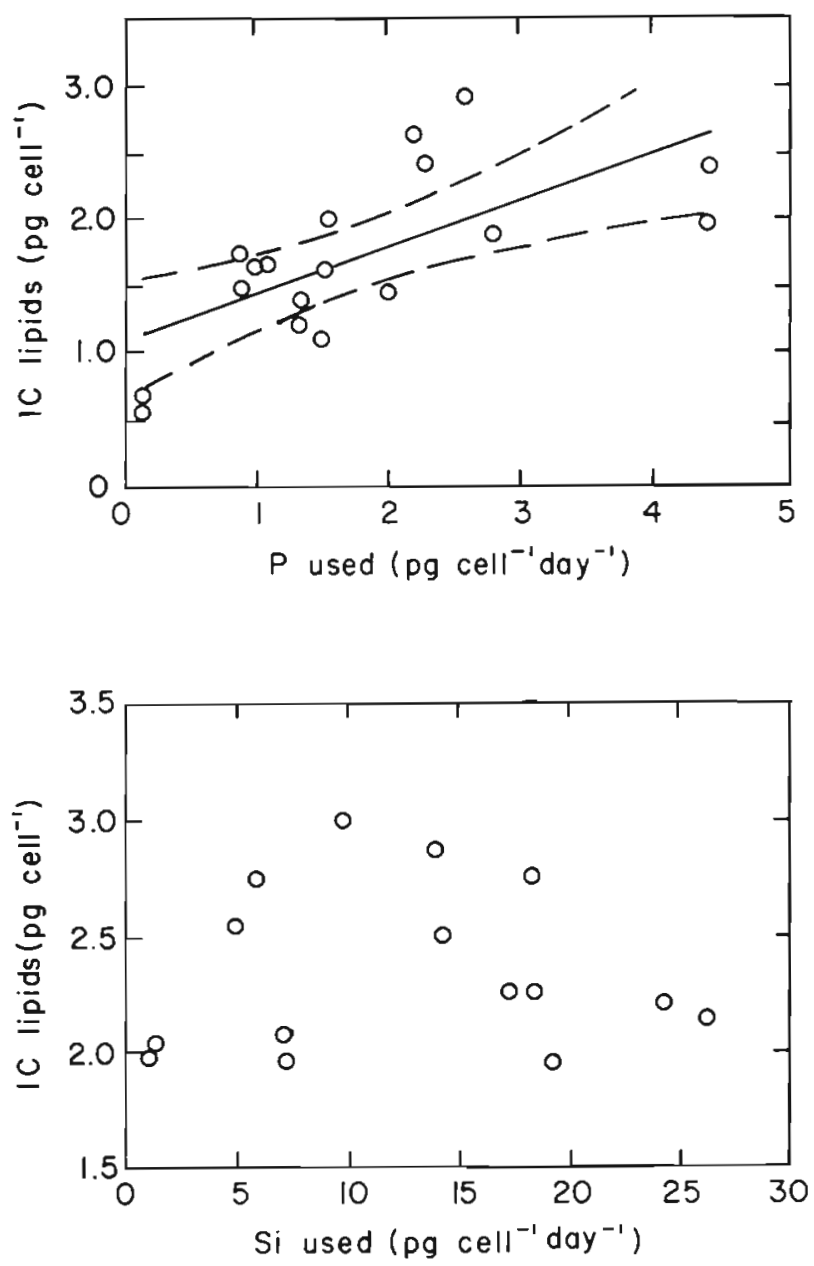

Fig. 9. Chaetoceros gracilis. Intracellular lipid yield (IC lipid) as function of the rate of nutrient used per cell. IC $=1.11+$ 0.34 ( $\mathrm{P}$ used), $\mathrm{r}=0.67, \mathrm{p}<0.01, \mathrm{n}=18$. There is no correlation with Si used

prove to be a better guide to the physiological state of a natural population than is the $\mathrm{C}: \mathrm{N}$ : P ratio; any triglyceride content greater than $15 \%$ of the total lipids would imply nutrient stress. It is interesting that silicon stress, which affects parts of the biosynthetic cycle different from those affected by nitrogen and phosphorus stress, still results in the accumulation of lipid storage products.

The decrease in chlorophyll a content per cell observed in phosphorus stress has also been shown for Phaeodactylum tricornutum (Roy 1988) under nitrogen stress; it was an expected outcome of nutrient deprivation, and had been found for phosphorus deprivation by many investigators (e.g. Kuhl 1974, Healey \& Hendzel 1975). The subject has been discussed by Cembella et al. (1984). However, the increase in this pigment with decreasing silicon uptake was not expected. There are few studies linking silicon supply with chlorophyll synthesis; Holmes (1966), investigating the cytological effects of nutrient stress on diatoms, found increases in chlorophyll a content in cells undergoing silicon stress, while Werner (1977) and Volcani (1978) reported the opposite. This effect may be species-specific, but at least in C. gracilis the signal is unmistakeable.

The increase in pigment per cell suggests an unequal decrease under silicon stress in the processes involved in the photosynthetic cycle and those resulting in the formation of new cells in Chaetoceros gracilis. A similar phenomenon has been noted in the culture of the toxic dinoflagellate Alexandrium tamarense, where stresses such as phosphorus deprivation (Boyer et al. 1987) or light or temperature decrease (Ogata et al. 1987), which decrease the population growth rate, result in an increase in toxin concentration per cell.

If this effect is found to be general in diatoms, our interpretations of diatom productivity based on chlorophyll a content will have to be modified. There is a considerable literature linking increases in chlorophyll content per cell with decreases in light intensity and therefore with recent position in the water column or with self-shading in blooms (Meeks 1974 and references therein). Such increases may equally well be caused by silicon deficiency; an analysis for triglyceride content may be necessary to distinguish between the possibilities.

The use of chlorophyll a as a measure of biomass in the estimation of primary production by remote sensing (Platt 1986) may also be subject to error in particular cases. If a diatom bloom is brought to an end by exhaustion of silicon, the increase in chlorophyll a per cell in the final stages of the bloom will result in an overestimation of biomass, and therefore of primary productivity. A bloom may continue to give an appearance of high productivity at a time when population growth is actually slowing down drastically. Measurements of triglyceride or chlorophyll content per cell - at least at present not possible by remote sensing - may be needed in order to determine whether chlorophyll can be used as a phytoplankton biomass estimator. Since silicon limitation would not be expected to influence the chlorophyll content of those cells without a siliceous skeleton, the uncertainty in our knowledge of the chemical composition of the phytoplankton sets limits on the reliability of productivity estimates from remote sensing data.

A major component of the lipids was the acetone mobile polar lipid fraction, which in unstressed cells could contain as much as $35 \%$ chlorophyll a. Both silicon and phosphorus stress decreased the rate of production of AMPL, but to different extents (Fig. 5). The differences in the slopes of the 2 lines can be explained by the effects of nutrient stress on the production of chlorophyll a already noted.

In phosphorus stressed cultures, a decrease in phospholipid synthesis was also observed. That this is not 
simply due to lack of available phosphorus was shown by the production of a similar effect by nitrogen stress on both Phaeodactylum tricornutum (Parrish \& Wangersky 1987) and Chaetoceros gracilis (Parrish \& Wangersky 1990), and to a lesser extent by silicon stress in the present paper (Table 1).

We found no significant variation in the production of aliphatic hydrocarbons (HC), free sterols (ST), and free fatty acids (FFA) over the whole range of silicon and phosphorus supplied to the cultures. High values of FFA, greater than $5 \%$, were probably the result of the action of lipases freed during sample preparation, and should be interpreted with caution.

Although an increase in total lipid per cell was found under both phosphorus and silicon stress (Fig. 7), decreased population growth resulted in a lower particulate yield (Fig. 9). The middle range of nutrient concentrations used in these experiments produced a combination of population growth rates and lipid concentrations resulting in the highest yields of intracellular lipids.

Roessler (1988) demonstrated that the accumulation of lipids in the diatom Cyclotella cryptica under silicon deficiency was due to 2 separate processes: increase in the proportion of neutral lipids in the newly assimilated carbon, and slow conversion of previously assimilated carbon from non-lipid material into the lipid fraction. This process of conversion is undoubtedly the reason for the many literature reports of increased lipid production in senescent batch cultures.

\section{Extracellular lipids}

It has been suggested that healthy phytoplankton release only a small portion of their photosynthetically fixed organic carbon into the ambient medium, and that the increase in dissolved organic material found in senescent cultures results to a large extent from cell lysis (Wangersky 1978). The present investigation showed that total production of dissolved lipids by Chaetoceros gracilis was not greatly affected by nutrient stress. Of the 6 lipid classes, only the phospholipids displayed any increase in the medium. This increase was probably due to the breakdown of cell membranes, an effect which could be observed under the microscope. Similarly, Parrish \& Wangersky (1987) observed no increase in the lipid content of the medium when Phaeodactylum tricornutum was subjected to nitrogen stress.

\section{CONCLUSIONS}

At low phosphorus delivery rates, cultures of Chaetoceros gracilis removed essentially all of the phosphorus from the medium. On the other hand, there appeared to be a threshold level below which siljcon was not taken up. In $C$. gracilis, either phosphorus, silicon or, as previously shown, nitrogen stress will trigger the increased synthesis of triglycerides, a class of storage compounds. The same effect has been seen in cultures of Phaeodactylum tricornutum undergoing nitrogen stress, and in the final stages of natural phytoplankton blooms. A high triglyceride level may be the best indicator of nutrient stress in diatoms.

Phosphorus stress resulted in a decrease in the polar lipid class, composed largely of phospholipids, as well as a decrease in chlorophyll a content. Silicon stress, on the other hand, resulted in an increase in the chlorophyll a content per cell; this finding has implications on the use of chlorophyll a as a measure of biomass, and as a clue to the recent depth history of a population.

The other lipid classes showed little change in cultures subjected to silicon or phosphorus stress, or in the medium in which these cultures had been grown.

While there is an increase in total lipids per cell under nutrient stress, due to the large increase in triglyceride content, the decrease in population growth rate results in an overall decrease in total cellular lipid yield. The high lipid content often described for senescent cultures probably results from the conversion of existing compounds in older cells into lipids, rather than from the fixation of carbon into lipids in newly formed cells.

Acknowledgements. The excellent technical assistance furnished by R. L. Maass and B. Schofield is greatfully acknowledged. A research scholarship from the World University Service of Canada supported ATL; the Brazilian Government Agency (CNPq) is acknowledged. Research funding was also received by P.J.W. from the Natural Sciences and Engineering Research Council of Canada. Writing of the final version of this paper was funded by the Dirección General de Investigación Cientifica y Téchnica (DGICYT) of Spain

\section{LITERATURE CITED}

Boyer, G. L., Sullivan, J. J., Andersen, R. J., Harrison, P. J. Taylor, F. J. R. (1987). Effects of nutrient limitation on toxin production and composition in the marine dinoflagellate Protogonyaulax tamarensis. Mar. Biol. 96: 123-128

Cembella, A. D., Antia, N. J., Harrison, P. J. (1984). The utilization of phosphorus compounds as nutrients by eukaryotic microalgae: a multidisciplinary perspective. Part 2. CRC Critical Rev. Microbiol. 11 13-81

Collyer, D. M., Fogg, G. E. (1989). Studies on fat accumulation by algae. J. exp. Bot. 6: 256-275

Emdadi, D., Berland, B. (1989). Variation in lipid class composition during batch growth of Nannochloropsis salina and Pavlova lutheri. Mar. Chem. 26: 215-225

Fogg, G. E. (1956). Photosynthesis and formation of fats in a diatom. Ann. Bot. 20: 265-285

Gershey, R. M., Wangersky, P. J. (1986). Comparison of TLC- 
FID and high resolution gas chromatography for the analysis of seawater lipids. NRC Contr. Rept. No DSS 09SC.31028-4-5304Y, 27 pp.

Harrison, P. J., Waters, R. E.. Taylor, F. R. J. (1980). A broad spectrum artificial seawater medium for coastal and open ocean phytoplankton. J. Phycol. 16: 28-35

Healey, L. P., Hendzel, L. L. (1975). Effect of phosphorus deficiency on two algae growing in chemostats. J. Phycol. 11: 303-309

Holmes, R. W (1966). Light microscope observations on cytological manifestations of nitrate, phosphate and silicate deficiency in four marine centric diatoms. J. Phycol. 2: 136-140

Korollef, F. (1976). Determination of silicon. In: Grasshoff, K. (ed.) Methods of seawater analysis. Verlag Chemie, New York, p. 149-157

Kuhl, A. (1974). Phosphorus. In: Stewart, W D. (ed.) Algal physiology and biochemistry. Univ. of California Press, California, p. 636-654

Meeks, J. C. (1974). Chlorophylls. In: Stewart, W. D. (ed.) Algal physiology and biochemistry. Univ. of California Press, California, p. 161-175

Morris, R. J., McCartney, M. J., Robinson, G. A. (1983). Studies of a spring phytoplankton bloom in an enclosed experimental ecosystem. I. Biochemical changes in relation to the nutrient chemistry of water. J. exp. mar Biol. Ecol. 70: 249-262

Mortensen, S. H., Borsheim, K. Y., Rainuzzo, J. R., Knutsen, G. (1988). Fatty acid and elemental composition of the marine diatom Chaetoceros gracilis Shütt. Effects of silicate deprivation, temperature and light intensity. J. exp. mar. Biol. Ecol. 122: 173-185

Ogata, T., Ishimaru, T., Kodama, M. (1987). Effect of water temperature and light intensity on growth rate and toxicity change in Protogonyaulax tamarensis. Mar. Biol. 95: $217-220$

Opute, F. L. (1974). Lipid and fatty-acid composition of diatoms. J. exp. Bot. 25: 823-835

Parrish, C. C. (1987a). Time series of particulate and dissolved lipid classes during spring phytoplankton blooms in Bedford Basin, a marine inlet. Mar Ecol. Prog. Ser. 35: $129-139$

Parrish, C. C. (1987b). Separation of aquatic lipid classes by Chromarod thin-layer chromatography with measurement by Iatroscan flame ionization detection. Can. J. Fish. Aquat. Sci. 44: 722-731

This article was submitted to the editor
Parrish, C. C., Wangersky, P. J. (1987). Particulate and dissolved lipid classes in cultures of Phaeodactylum tricornutum grown in cage culture turbidostats with a range of nitrogen supply rates. Mar. Ecol. Prog. Ser 35: 119-128

Parrish, C. C., Wangersky, P. J. (1990). Growth and lipid class composition of the marine diatom, Chaetoceros gracilis, in laboratory and mass culture turbidostats. J. Plankt. Res. 12: $1011-1021$

Platt, T (1986). Primary production of the ocean water column as a function of surface light intensity: algorithms for remote sensing. Deep Sea Res. 33: 149-163

Roessler, P. G. (1988). Effects of silicon deficiency on lipid composition and metabolism in the diatom Cyclotella cryptica. J. Phycol. 24: 394-400

Roy, S. (1988). Effecs of change in physiological conditions on HPLC-defined chloropigment composition of Phaeodactylum tricornutum (Bohlin) in batch and turbidostat cultures. J. exp. mar. Biol. Ecol. 118: 137-149

Shifrin, N. S., Chisholm, S. W. (1981). Phytoplankton lipids: interspecific differences and effects of nitrate, silicate and light-dark cycles. J. Phycol. 17: 374-384

Skipnes, O., Eide, I., Jensen, A. (1980). Cage culture turbidostat: a device for rapid determination of algal growth rate. Appl. environ. Microbiol. 40: 318-325

Strickland, J. D. H., Parsons, T R. (1972). A practical handbook of seawater analysis. Bull. Fish. Res. Bd Can. 167

Taguchi, S., Hirata, J. A., Laws, E. A. (1987). Silicate deficiency and lipid synthesis of marine diatoms. J. Phycol. 23: 260-267

Talling, J. F., Driver, D. (1961). Some problems in the estimation of chlorophyll-a in phytoplankton. 10th Pacif. Sci. Cong., Honolulu, p. 142-146

Volcani, B. E. (1978). Role of silicon in diatom metabolism and silification. In: Bendz, G., Lindqvist, I. (eds.) Biochemistry of silicon and related problems. Plenum Press, New York, p. $177-204$

Wangersky, P. J. (1978). Production of dissolved organic matter. In: Kinne, O. (ed.) Marine ecology, Vol. IV, Dynamics. John Wiley and Sons, New York, p. 115-220

Werner, D. (1977). Silicate metabolism. In: Werner, D. (ed.) The biology of diatoms. Blackwell Scientific Publ., Oxford, p. $110-149$

Zhou, X. Wangersky, P. J. (1989). Production of coppercomplexing organic ligands by a marine diatom, Phaeodactylum tricornutum, in a cage culture turbidostat Mar. Chem. 26: 239-259

Manuscript first received: February 14, 1990

Revised version accepted: August 6, 1991 